\title{
Dent's disease
}

\author{
Olivier Devuyst ${ }^{1 *}$, Rajesh V Thakker ${ }^{2}$
}

\begin{abstract}
Dent's disease is a renal tubular disorder characterized by manifestations of proximal tubule dysfunction, including low-molecular-weight proteinuria, hypercalciuria, nephrolithiasis, nephrocalcinosis, and progressive renal failure. These features are generally found in males only, and may be present in early childhood, whereas female carriers may show a milder phenotype. Prevalence is unknown; the disorder has been reported in around 250 families to date. Complications such as rickets or osteomalacia may occur. The disease is caused by mutations in either the CLCN5 (Dent disease 1) or OCRL1 (Dent disease 2) genes that are located on chromosome Xp11.22 and Xq25, respectively. CLCN5 encodes the electrogenic $\mathrm{Cl}^{-} / \mathrm{H}^{+}$exchanger $\mathrm{CIC}-5$, which belongs to the $\mathrm{CLC}$ family of $\mathrm{Cl}^{-}$channels/transporters. OCRL1 encodes a phosphatidylinositol bisphosphate $\left(\mathrm{PIP}_{2}\right)$ 5-phosphatase and mutations are also associated with Lowe Syndrome. The phenotype of Dent's disease is explained by the predominant expression of CIC-5 in the proximal tubule segments of the kidney. No genotype-phenotype correlation has been described thus far, and there is considerable intra-familial variability in disease severity. A few patients with Dent's disease do not harbour mutations in CLCN5 and OCRL1, pointing to the involvement of other genes. Diagnosis is based on the presence of all three of the following criteria: low-molecular-weight proteinuria, hypercalciuria and at least one of the following: nephrocalcinosis, kidney stones, hematuria, hypophosphatemia or renal insufficiency. Molecular genetic testing confirms the diagnosis. The differential diagnosis includes other causes of generalized dysfunction of the proximal tubules (renal Fanconi syndrome), hereditary, acquired, or caused by exogenous substances. Antenatal diagnosis and pre-implantation genetic testing is not advised. The care of patients with Dent's disease is supportive, focusing on the treatment of hypercalciuria and the prevention of nephrolithiasis. The vital prognosis is good in the majority of patients. Progression to end-stage renal failure occurs between the $3^{\text {rd }}$ and $5^{\text {th }}$ decades of life in $30-80 \%$ of affected males.
\end{abstract}

\section{Disease name and synonyms}

Dent disease 1 (OMIM \#300009)

X-linked recessive nephrolithiasis (OMIM \#310468)

$\mathrm{X}$-linked recessive hypercalciuric hypophosphataemic rickets (OMIM \#300554)

Low-molecular-weight proteinuria with hypercalciuria and nephrocalcinosis (OMIM \#308990)

Dent disease 2 (OMIM \#300555)

\section{Definition and epidemiology}

Dent's disease (OMIM \#300009) refers to a heterogeneous group of X-linked disorders that have previously been reported as $\mathrm{X}$-linked recessive nephrolithiasis, $\mathrm{X}$-linked hypercalciuric hypophosphataemic rickets, or idiopathic low-molecular-weight proteinuria with

\footnotetext{
* Correspondence: olivier.devuyst@uclouvain.be

'Division of Nephrology, Université catholique de Louvain Medical School, Brussels, Belgium

Full list of author information is available at the end of the article
}

hypercalciuria and nephrocalcinosis [1-6]. The disease is characterized by manifestations of proximal tubule (PT) dysfunction associated with hypercalciuria, nephrolithiasis, nephrocalcinosis, and progressive renal failure [7]. Low-molecular-weight (LMW) proteinuria represents the most consistent manifestation of Dent's disease, detected in almost all affected males and obligate female carriers. There is considerable inter- and intra-familial variability in the other manifestations of PT dysfunction, which may cause a renal Fanconi syndrome with hypophosphataemic rickets, as well as in the extent of nephrocalcinosis/nephrolithiasis. Dent's disease is a rare disorder, with around 250 affected families reported to date $[8,9]$.

\section{Clinical description}

Dent's disease is characterized by PT dysfunction and LMW proteinuria, associated with hypercalciuria, nephrolithiasis, nephrocalcinosis, and progressive renal
C Biomed Central

() 2010 Devuyst and Thakker; licensee BioMed Central Ltd. This is an Open Access article distributed under the terms of the Creative Commons Attribution License (http://creativecommons.org/licenses/by/2.0), which permits unrestricted use, distribution, and reproduction in any medium, provided the original work is properly cited. 
failure. Dent's disease may also be associated with aminoaciduria, phosphaturia, glycosuria, uricosuria, kaliuresis, and impaired urinary acidification, and is often complicated by rickets or osteomalacia [4]. These features are generally found in males only, who may have manifestations of the disease from early childhood $[7,8,10]$. These patients may present with bone pain and difficulty in walking due to rickets, or symptoms of renal stones such as abdominal pain and haematuria. Occasionally, patients are referred as a result of the fortuitous discovery of biological manifestations of PT dysfunction, including LMW proteinuria. LMW proteinuria, which is characterised by the excretion of proteins such as $\alpha 1$ and $\beta 2$ microglobulins, retinolbinding protein (RBP), Clara cell protein, and vitamin $\mathrm{D}$ binding protein, is found in approximately $99 \%$ of affected males. It has been hypothesized recently that the urinary loss of RBP may cause episodic night blindness in some patients [11]. Hypercalciuria and nephrocalcinosis are also highly prevalent and occur in 95\% and $75 \%$ of affected males respectively, although there is considerable inter- and intra-familial variability in the occurrence of nephrolithiasis which occurs in approximately $50 \%$ of affected males. Progression to end-stage renal failure occurs between the $3^{\text {rd }}$ and the $5^{\text {th }}$ decades of life in $30-80 \%$ of affected males [7]. These manifestations of Dent's disease may occur occasionally in females. For example, the milder features of LMW proteinuria and hypercalciuria are found in approximately $70 \%$ and $50 \%$ of females carriers, respectively, whilst the more severe manifestations of nephrolithiasis have been reported in only 10 females and end-stage renal failure has been reported in only 1 female [8]. Like other tubulopathies, Dent's disease has been associated with rare cases of proteinuria and biopsy-proven focal glomerulosclerosis [12]. The occurrence of these predominantly renal manifestations and their association with causative mutations in ClC-5 (see below) is referred to as Dent disease 1.

Some patients with Dent's disease have been observed to have extra-renal manifestations such as mild intellectual impairment [1], hypotonia and cataract, and such patients have been reported to share mutations in OCRL1 with the oculo-cerebrorenal syndrome of Lowe $[9,13]$. The occurrence of these extra-renal manifestations with mutations relating to Lowe syndrome is referred to as Dent disease 2 [13]. To date, around 20 patients with Dent disease 2 have been reported, all of whom have hypercalciuria and LMW proteinuria. In addition, these patients may also have nephrocalcinosis, nephrolithiasis, haematuria, hypophosphataemia and/or renal insufficiency. Only a minority (approximately onefourth) of these patients have been observed to have mild intellectual deficit, hypotonia and sub-clinical cataract. It is important to note that the presence of intellectual impairment and sub-clinical cataract were so mild as to dissuade the clinicians from considering a diagnosis of Lowe's syndrome, which is characterised by congenital cataracts, delayed motor milestones, some degree of intellectual impairment in almost all affected males, growth retardation, rickets and renal proximal tubulopathy. Moreover, the patients with Dent disease 2 and mild intellectual deficit were adults, who had not, over time, developed more overt features of Lowe's syndrome $[9,13]$.

\section{Genetics}

Dent's disease may be caused by either inactivating mutations in CLCN5 (OMIM \#300008), which is located on chromosome Xp11.22 and encodes a 746 amino-acid electrogenic $\mathrm{Cl}^{-} / \mathrm{H}^{+}$exchanger $(\mathrm{ClC}-5)[5,14]$, or the OCRL1 gene, which is located on chromosome $\mathrm{Xq} 25$ and encodes the phosphatidylinositol 4,5-biphosphate 5-phosphatase OCRL1 [13]. ClC-5 contains $18 \alpha$-helices, with two phosphorylation and one $\mathrm{N}$-glycosylation sites. Structural studies have revealed that the protein forms diamond-shaped homodimers composed of two repeated halves that span the membrane in opposite orientations. Each subunit has its own pore responsible for the selective coupling of the $\mathrm{Cl}^{-}$flux to $\mathrm{H}^{+}$counter-transport [15]. The total number of reported CLCN5 mutations is 148 , and these are scattered throughout the coding region, with no evidence for major mutational hot spots [8]. Furthermore, there appears to be no correlation between the mutations and phenotypes and/or between the presence or absence of a CLCN5 mutation and the Dent's disease phenotype. Of the total 148 CLCN5 mutations, approximately $36 \%$ are nonsense mutations, $33 \%$ are missense mutations, $14 \%$ are frameshift deletions, $5 \%$ are frameshift insertions, $3 \%$ are donor splice site mutations, $3 \%$ are acceptor splice site mutations, $2 \%$ are intragenic deletions, $1 \%$ are novel splice site mutations, $1 \%$ are complete deletions of the gene, $1 \%$ are inframe insertions, and $1 \%$ are in-frame deletions. The majority are predicted to result in truncated or absent ClC-5 protein, which would lead to complete loss of antiporter function. Indeed heterologous expression of these Dent's disease CLCN5 mutants, in either Xenopus laevis oocytes or HEK293 cells, has revealed that the majority of CLCN5 mutations lead to a loss of $\mathrm{Cl}^{-}$conductance [5]. Further detailed studies of the CLCN5 missense mutations have revealed that these may lead to one of three abnormalities; endoplasmic reticulum retention and degradation of $\mathrm{ClC}-5$, defective endosomal acidification, or altered endosomal distribution of ClC-5 but not defective endosomal acidification [16]. Of note, the majority of the missense mutations are clustered at the interface between the two subunits, emphasizing the 
functional importance of ClC-5 homodimerisation [17]. Furthermore, genetic inactivation of the $\mathrm{Clcn} 5$ gene in mice mimics the severe PT dysfunction observed in Dent's disease, including hypercalciuria and nephrocalcinosis (see below).

Approximately $40 \%$ of patients with Dent's disease do not have CLCN5 mutations, even though they are clinically indistinguishable from those that have CLCN5 mutations [8]. Twenty of these patients have been reported to have OCRL1 mutations $[9,13]$, although it is important to note that none of these had the severe cataracts or intellectual deficit that is typically found in patients with Lowe syndrome. Consistent with these phenotypic differences, it is interesting to note that the OCRL1 mutations associated with Dent disease 2 do not overlap with those causing Lowe syndrome. All of the OCRL1 missense mutations associated with Dent's disease occur in the 5 ' region of the gene (exons 4 to 15) and involve the phosphatidylinositol phosphate 5phosphatase domain of the OCRL1 protein, whilst the truncating mutations are in the first seven exons or intron 7. By contrast, the OCRL1 mutations that are found in Lowe syndrome patients occur primarily in exons 9-22, which encode the 3 large functional domains [9]. A model in which a reduced but functioning form or isoform of OCRL1 protein is expressed in Dent disease 2, but not Lowe syndrome, has been proposed to explain the milder phenotypic features observed in the former patients [9]. Thus, there is genetic heterogeneity for Dent's disease, with approximately $50-60 \%$ of patients having CLCN5 mutations (Dent disease 1), $15 \%$ harbouring OCRL1 mutations (Dent disease 2) and the remaining $25-35 \%$ of patients having neither CLCN5 nor OCRL1 mutations but possibly defects in other genes. The possibility that these other genes may encode some of the proteins (e.g. ClC4 and cofilin) that interact with $\mathrm{ClC}-5$ [18] has been investigated but no mutations in CLCN4 or COFILIN were identified [8].

\section{Pathophysiology}

The complex phenotype of Dent disease 1 is probably explained by the predominant expression of $\mathrm{ClC}-5$ in the PT segments, with more discrete expression in the thick ascending limb (TAL) of Henle's loop and the $\alpha$-type intercalated cells (IC) of the collecting ducts of the kidney [19]. In PT cells, ClC-5 co-distributes with the vacuolar $\mathrm{H}^{+}$-ATPase (V-ATPase) in early endosomes $[19,20]$, which are responsible for the reabsorption and processing of albumin and LMW proteins that are filtered by the glomerulus (Figure 1). These vesicles belong to the receptor-mediated endocytic pathway, which involves the multiligand receptors, megalin and cubilin, located at the apical brush border of PT cells
[21]. Progression along the endocytic apparatus depends on endosomal acidification, driven by the V-ATPase and requiring a parallel $\mathrm{Cl}^{-}$conductance to maintain electroneutrality. It has long been assumed that $\mathrm{ClC}-5$ could provide such an electrical shunt to neutralize the $\mathrm{H}^{+}$ gradient. Accordingly, the loss of the endosomal $\mathrm{Cl}^{-}$ conductance mediated by $\mathrm{ClC}-5$ would impair vesicular acidification, causing dysfunction of PT cells. Two independent strains of ClC-5 knock-out (KO) mice have been generated, which both recapitulate the major features of Dent's disease including LMW proteinuria and other manifestations of PT dysfunction [22,23]. Furthermore, in vitro experiments have shown a decreased acidification of early endosomes in $\mathrm{ClC}$-5-deficient mice $[24,25]$.

However, $\mathrm{ClC}-5$ is a $2 \mathrm{Cl}^{-} / \mathrm{H}^{+}$exchanger rather than a $\mathrm{Cl}^{-}$channel [14], and the relevance of this exchange activity for Dent's disease was unknown. To address that important issue, Jentsch and colleagues engineered a knock-in (KI) mouse harbouring a point mutation in a critical glutamate residue which converts the exchanger into an uncoupled $\mathrm{Cl}^{-}$channel that should facilitate endosomal acidification. They then compared these KI mice with the conventional ClC-5 $\mathrm{KO}$ mouse [26]. As expected, acidification of the renal endosomes from wild-type and KI mice was normal, but severely impaired in $\mathrm{KO}$ mice. However, despite normal endosomal acidification, KI mice showed the same renal phenotype than KO mice and patients with Dent's disease, including LMW proteinuria, hyperphosphaturia and hypercalciuria. Furthermore, both the KI and KO mouse showed impaired PT endocytosis, indicating that PT dysfunction in Dent's disease may occur despite normal acidification of the endosomes. These findings suggest a role for a reduced endosomal $\mathrm{Cl}^{-}$accumulation in Dent's disease and, by extension, point to the importance of $\mathrm{Cl}^{-}$concentration for organelle physiology [26].

Studies in mice have demonstrated that inactivation of ClC- 5 is associated with a severe trafficking defect in PT cells, with loss of megalin and cubilin at the brush border, subsequent loss of their ligands in the urine, and impaired lysosomal processing [22,23,27]. Since the megalin/cubilin complex mediates the reabsorption of the vitamin D-binding protein, the $25(\mathrm{OH})$-vitamin D3 and parathyroid hormone (PTH) that are ultrafiltrated by the glomerulus, the urinary loss of these mediators could potentially lead to opposite effects in PT cells, resulting in variable levels of active $1,25(\mathrm{OH})_{2}$-vitamin $\mathrm{D}_{3}$ levels in the serum [28]. Such variability could explain why renal hypercalciuria and kidney stones are present in one strain of ClC-5 $\mathrm{KO}$ mouse [23] but not in the other [22], potentially reflecting the phenotype variability observed in patients harbouring $\mathrm{ClC}-5$ mutations [7]. Recently, Gailly et al. showed that the deletion 


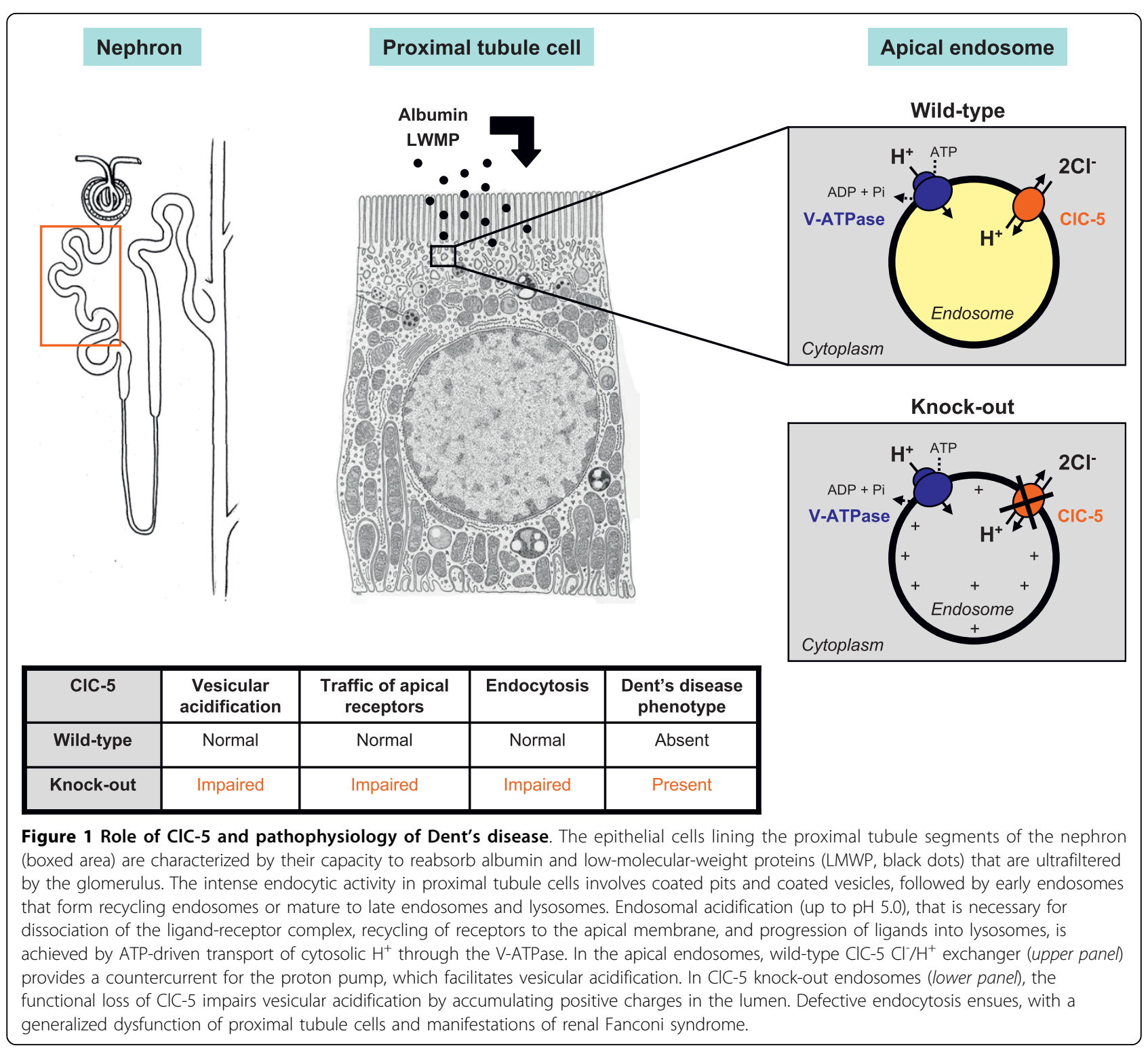

of $\mathrm{ClC}-5$ in mouse and human PT cells is associated with increased cell proliferation, oxidative stress and the specific induction of type III carbonic anhydrase [29]. Furthermore, $\mathrm{ClC}-5$ inactivation is associated with impaired lysosome biogenesis, which also contributes to defective endocytosis and urinary loss of LMW ligands and lysosomal enzymes [30]. It must be emphasized that other inherited disorders targeting the PT cells, such as lysosomal storage disorders (cystinosis) or mitochondrial cytopathies, may result in PT dysfunction similar to that observed in Dent's disease [31].

The potential roles of $\mathrm{ClC}-5$ in the TAL (involved in the urinary concentration mechanism and the regulated reabsorption of divalent cations) [32] and in the $\alpha$-type IC (responsible for distal urinary acidification) remain to be defined [33]. Of interest, CLCN5 mutations have not been detected in patients with idiopathic hypercalciuria and in the hypercalciuric stone-forming (GHS) rat strain [34]. The hypercalciuria observed in patients with Dent's disease and some $\mathrm{ClC}$-5-deficient mice may be secondary to the PT dysfunction (urinary loss of vitamin D binding protein and reduced phosphate absorption, leading to increased $1,25(\mathrm{OH})_{2}$-vitamin $\mathrm{D}_{3}$ synthesis) or, at least in part, caused by the functional loss of $\mathrm{ClC}-5$ in the TAL. A small fraction of patients with Dent's disease may have nephrocalcinosis without hypercalciuria [10], which could indeed reflect the fact that $\mathrm{ClC}-5$ is distributed in several nephron segments that can contribute to the genesis of kidney stones through different mechanisms. For instance, it has been suggested that collecting 
duct cells lacking $\mathrm{ClC}-5$ may show an impaired ability of internalization of calcium crystals adhering to apical cell surface [35]. In summary, we can hypothesize that the functional loss of $\mathrm{ClC}-5$ is essentially reflected by manifestations of PT dysfunction and may contribute to the genesis of kidney stones in different ways, reflecting its involvement in specific tubular functions. The issue is further complicated by the existence of a significant inter- and intra-familial variability in the manifestations of nephrocalcinosis and kidney stones.

Although ClC-5 mRNA and protein are detected in rodent intestine [36] and thyroid [37], no clear phenotype related to these tissues has been reported in patients. Of note, $\mathrm{ClC}-5$ is highly expressed in the mouse thyroid, located in various endosomes at the apical pole of the thyrocytes. Mice lacking $\mathrm{ClC}-5$ develop a euthyroid goiter, which results from impaired apical iodide efflux (secondary to down-regulated pendrin) rather than defective apical endocytosis [37].

The phenotype of Dent disease 2 due to OCRL1 mutations may in part be attributed to the role of OCRL1 in lysosomal trafficking and endosomal sorting. OCRL1 encodes a member of the type II family if inositol polyphosphate 5-phosphatases [38]. These enzymes hydrolyze the 5-phosphate of inositol 1, 4, 5-trisphosphate and of inositol 1,3,4,5-tetrakisphosphate, phosphatidylinositol 4,5-bisphosphate, and phosphatidylinositol 3,4,5trisphosphate, thereby presumably inactivating them as second messengers in the phosphatidylinositol signalling pathway [39]. The preferred substrate of OCRL1 is phosphatidylinositol 4,5-bisphosphate ( $\left.\mathrm{PIP}_{2}\right)$, and this lipid accumulates in the renal PT cells of patients with Lowe syndrome [39]. OCRL1 is localised to lysosomes in renal PT cells and to the trans-Golgi network in fibroblasts. This localisation is consistent with the role of OCRL1 in lysosomal enzyme trafficking from the trans-Golgi network to lysosomes, and the activities of several lysosomal hydrolases are found to be elevated in the plasma of affected patients [40]. OCRL1 has also been shown to interact with clathrin and indeed colocalises with clathrin on endosomal membranes that contain tranferrin and mannose 6-phosphate receptors [41]. Mannose 6-phosphate receptor-bound lysosomal enzymes are recruited by appendage (AP) subunits and Golgi-localised binding proteins into clathrin-coated vesicles that transport them from the trans-Golgi network to endosomes [41]. More recently, Erdmann et al. showed that OCRL1 plays a role in the early endocytic pathway, by interacting with the Rab5 effector APPL1 [42]. Thus, it seems likely that the OCRL1 mutations in Lowe syndrome patients result in OCRL1 protein deficiency, which leads to disruptions in the endosomal and/or lysosomal trafficking. This abnormality is similar to that observed in Dent disease 1, and it seems that
Dent's disease therefore may be due to abnormalities in either endosomal acidification and sorting, or lysosomal trafficking. It must be noted that the targeted disruption of the murine ortholog for OCRL1 does not cause Lowe syndrome, because Ocrl1 deficiency is complemented in mice by inositol polyphosphate 5-phosphatase (Inpp 5b) [43]. Thus, no mouse model recapitulating Lowe syndrome caused by the deficiency in OCRL1 is available.

\section{Diagnosis}

The clinical diagnosis of Dent's disease is based on the presence of all three of the following criteria: (i) LMW proteinuria (elevation of urinary excretion of $\beta 2$ microglobulin, Clara cell protein and/or RBP by at least 5-fold above the upper limit of normality); (ii) hypercalciuria $(>4 \mathrm{mg} / \mathrm{kg}$ in a $24 \mathrm{~h}$-hour collection or $>0.25$ $\mathrm{mg} \mathrm{Ca}{ }^{2+}$ per $\mathrm{mg}$ creatinine on a spot sample); and (iii) at least one of the following: nephrocalcinosis, kidney stones, hematuria, hypophosphataemia, or renal insufficiency. The clinical diagnosis is supported by a history of X-linked inheritance of renal Fanconi syndrome and/ or nephrolithiasis. The identification of mutation in either CLCN5 or OCRL1 confirms the diagnosis. However, some patients with CLCN5 mutations have been reported to have LMW proteinuria or hypercalciuria alone $[34,44]$, and thus in the presence of an identified CLCN5 mutation, only one of the above clinical criteria may be sufficient to establish an affected status in an individual. It is important to note that the absence of clinical cataracts and the lack of severe intellectual deficit are key features that make a diagnosis of Dent disease 2, associated with OCRL1 mutations, more likely than a diagnosis of Lowe syndrome.

There have been few reports of renal biopsies in cases with proven CLCN5 mutations [45]. Light microscopy studies revealed progressive, non-specific lesions that include glomerular hyalinosis, tubular cell degeneration or atrophy, and mild interstitial fibrosis. Of interest, these kidneys invariably showed hyaline casts that were sometimes calcified, located in the outer medulla and presumably the first manifestations of nephrocalcinosis. By contrast, electron microscopy did not reveal any ultrastructural abnormalities in PT cells [45].

\section{Differential diagnosis}

The differential diagnosis of Dent's disease includes the other causes of generalized PT dysfunction (renal Fanconi syndrome), that can be inherited, acquired or caused by exogenous substances [31,46] (Appendix 1).

\section{Genetic counselling}

Both forms of Dent's disease are X-linked, and males, who are hemizygous, are affected more severely. Females, who are usually only mildly affected, are 
carriers and will transmit the disease to half of their sons whereas half of their daughters will be carriers. All the daughters of affected males will be carriers as they will have inherited the $\mathrm{X}$ chromosome harbouring the mutation, but all the sons of affected fathers who will have inherited the $\mathrm{Y}$ chromosome and not the X chromosome, will be normal. In approximately $10 \%$ of patients, Dent's disease occurs de novo and a family history is absent, but the disease will be transmitted as an $\mathrm{X}$-linked trait to subsequent generations. If the mother or siblings of a patient with Dent's disease are eager to know their genetic status and risk for developing the disease, then mutational analysis of CLCN5 and/or OCRL1, using leukocyte DNA can be undertaken. However, it is important to note that it may not be routinely available in all genetic diagnostic laboratories. Although technically feasible, antenatal diagnosis and pre-implantation genetic testing for Dent's disease is not advised, and as yet has not been requested, because the vital prognosis in the majority of patients is good and there is no evidence for a genotype-phenotype correlation. Indeed the severity of the disease may vary considerably in individuals from the same family $[10,34,47]$.

\section{Treatment}

In the absence of therapy targeting the molecular defect, the current care of patients with Dent's disease is supportive, focusing on the prevention of nephrolithiasis. Thiazide diuretics can be used to treat hypercalciuria $[48,49]$ although significant adverse events, including hypovolemia and hypokalemia related to the primary tubulopathy, have been reported [49]. Similarly, treatment of rickets with vitamin D must be cautious since it may increase hypercalciuria. Studies performed on ClC-5-deficient mice suggest that long-term control of hypercalciuria by a high citrate diet delays progression of renal disease even in the apparent absence of stone formation [50].

\section{Conclusions}

Dent's disease is a renal tubular disorder caused by mutations in either the CLCN5 (Dent disease 1) or OCRL1 (Dent disease 2) genes that are located on chromosome Xp11.22 and Xq25, respectively. CLCN5 encodes the electrogenic $\mathrm{Cl}^{-} / \mathrm{H}^{+}$exchanger $\mathrm{ClC}-5$, which is primarily located in the endosomes of the PT cells. The pathophysiology of the disease is essentially due to defective receptor-mediated endocytosis causing a generalized dysfunction of PT cells. OCRL1 encodes a PIP 2 5-phosphatase and mutations are also associated with the oculo-cerebro-renal syndrome of Lowe, characterized by bilateral congenital cataract, severe mental retardation, and renal Fanconi syndrome. A few patients with Dent's disease do not harbour mutations in CLCN5 and OCRL1, pointing to the involvement of other genes. The care of patients with Dent's disease is supportive, focusing on the prevention of nephrolithiasis. The cautious use of thiazide diuretics has been suggested to treat the associated hypercalciuria.

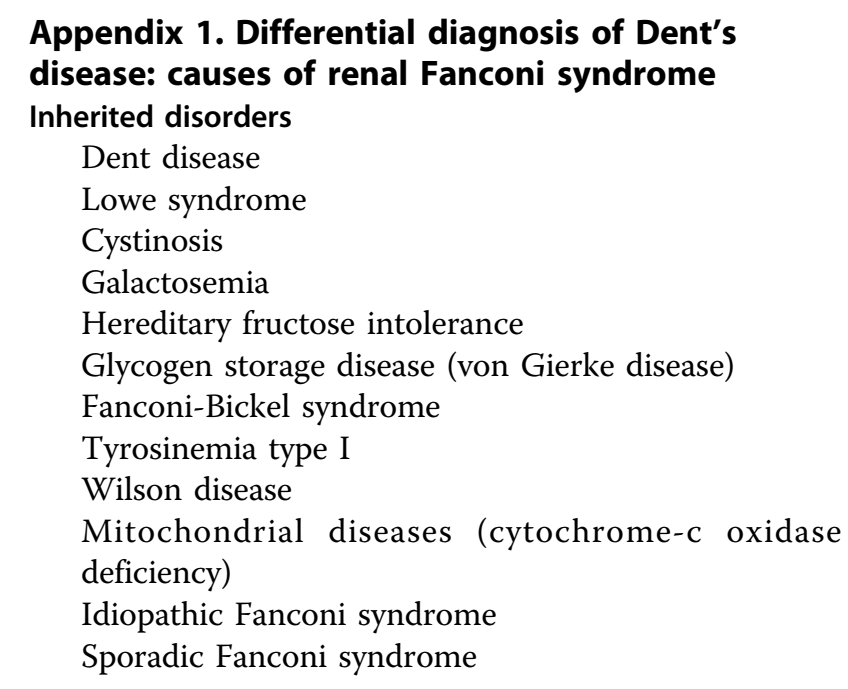

\section{Acquired disorders}

Glomerular proteinuria (nephrotic syndrome)

Light chain nephropathy (multiple myeloma)

Sjögren syndrome

Auto-immune interstitial nephritis

Acute tubulo-interestitial nephritis with uveitis (TINU)

Renal transplantation

Anorexia nervosa

\section{Exogenous substances}

Drugs

Aminoglycosides, outdated tetracycline

Valproate, salicylate

Adefovir, cidofovir, tenofovir

Ifosfamide, cisplatin, imanitib mesylate

Chinese herbs (aristolochic acid)

Chemical compounds (paraquat, diachrome, 6-mercaptopurine, toluene, maleate)

Heavy metals (lead, cadmium, chromium, platinum, uramnium, mercury)

\section{Abbreviations}

IC: intercalated cell; LMW:Iow-molecular-weight; PIP $_{2}$ : phosphatidylinositol [45] bisphosphate; PT: proximal tubule; PTH: parathyroid hormone; RBP: retinol binding protein; TAL: thick ascending limb (of Henle's loop); V: ATPase; vacuolar $\mathrm{H}^{+}$-ATPase 


\section{Acknowledgements}

OD's investigations were supported in part by the Belgian agencies FNRS and FRSM, the 'Fondation Alphonse \& Jean Forton', a Concerted Research Action (05/10-328), an Inter-university Attraction Pole (IUAP P6/05), the DIANE project (Communauté Française de Belgique) and the EUNEFRON (FP7, GA\#201590) program of the European Community; d RVT's investigations were supported by the Medical Research Council (MRC), UK, Wellcome Trust, and EuReGene (FP6).

\section{Author details}

'Division of Nephrology, Université catholique de Louvain Medical School, Brussels, Belgium. ${ }^{2}$ Academic Endocrine Unit, Nuffield Department of Medicine, Oxford Centre for Diabetes, Endocrinology and Metabolism (OCDEM), University of Oxford, Oxford, UK.

\section{Authors' contributions}

$\mathrm{OD}$ and RVT wrote the manuscript and approved its final version.

\section{Competing interests}

The authors declare that they have no competing interests.

Received: 7 December 2009 Accepted: 14 October 2010

Published: 14 October 2010

\section{References}

1. Dent $C E$, Friedman M: Hypercalcuric rickets associated with renal tubular damage. Arch Dis Child 1964, 39:240-249.

2. Pook MA, Wrong O, Wooding C, Norden AGW, Feest TG, Thakker RV: Dent's disease, a renal Fanconi syndrome with nephrocalcinosis and kidney stones, is associated with a micro-deletion involving DXS255 and maps to Xp11.22. Hum Mol Genet 1993, 2:2129-2134.

3. Scheinman SJ, Pook MA, Wooding C, Pang JT, Frymoyer PA, Thakker RV: Mapping the gene causing X-linked recessive nephrolithiasis to Xp11.22 by linkage studies. J Clin Invest 1993, 91:2351-2357.

4. Wrong OM, Norden AGW, Feest TG: Dent's disease; a familial proximal renal tubular syndrome with low-molecular-weight proteinuria, hypercalciuria, nephrocalcinosis, metabolic bone disease, progressive renal failure and a marked male predominance. Q J Med 1994, 87:473-493.

5. Lloyd SE, Pearce SH, Fisher SE, Steinmeyer K, Schwappach B, Scheinman SJ, Harding B, Bolino A, Devoto M, Goodyer P, Rigden SP, Wrong O, Jentsch TJ, Craig IW, Thakker RV: A common molecular basis for three inherited kidney stone diseases. Nature 1996, 379:445-449.

6. Lloyd SE, Pearce SHS, Günther W, Kawaguchi H, Igarashi T, Jentsch TJ, Thakker RV: Idiopathic low molecular weight proteinuria associated with hypercalciuric nephrocalcinosis in Japanese children is due to mutations of the renal chloride channel (CLCN5). J Clin Invest 1997, 99:967-974.

7. Scheinman SJ: X-linked hypercalciuric nephrolithiasis: clinical syndromes and chloride channel mutations. Kidney Int 1998, 53:3-17.

8. Wu F, Reed AA, Williams SE, Loh NY, Lippiat JD, Christie PT, Large O, Bettinelli A, Dillon MJ, Goldraich NP, Hoppe B, Lhotta K, Loirat C, Malik R, Morel D, Kotanko P, Roussel B, Rubinger D, Schrander-Stumpel C, Serdaroglu E, Nesbit MA, Ashcroft F, Thakker RV: Mutational Analysis of CLC-5, Cofilin and CLC-4 in Patients with Dent's Disease. Nephron Physiol 2009, 112:53-62.

9. Shrimpton AE, Hoopes RR Jr, Knohl SJ, Hueber P, Reed AA, Christie PT, Igarashi T, Lee P, Lehman A, White C, Milford DV, Sanchez MR, Unwin R, Wrong OM, Thakker RV, Scheinman SJ: OCRL1 mutations in Dent 2 patients suggest a mechanism for phenotypic variability. Nephron Physiol 2009, 112:27-36

10. Ludwig M, Utsch B, Balluch B, Fründ S, Kuwertz-Bröking E, Bökenkamp A Hypercalciuria in patients with CLCN5 mutations. Pediatr Nephrol 2006 21:1241-1250.

11. Sethi SK, Ludwig M, Kabra M, Hari P, Bagga A: Vitamin A responsive night blindness in Dent's disease. Pediatr Nephrol 2009, 24:1765-1770.

12. Copelovitch L, Nash MA, Kaplan BS: Hypothesis: Dent disease is an underrecognized cause of focal glomerulosclerosis. Clin J Am Soc Nephrol 2007, 2:914-918.

13. Hoopes RR Jr, Shrimpton AE, Knohl SJ, Hueber P, Hoppe B, Matyus J, Simckes A, Tasic V, Toenshoff B, Suchy SF, Nussbaum RL, Scheinman SJ: Dent Disease with mutations in OCRL1. Am J Hum Genet 2005, 76:260-267.
14. Scheel O, Zdebik AA, Lourdel S, Jentsch TJ: Voltage-dependent electrogenic chloride/proton exchange by endosomal CLC proteins. Nature 2005, 436:424-427.

15. Dutzler R, Campbell EB, Cadene M, Chait BT, Mackinnon R: X-ray structure of a CIC chloride channel at 3.0 A reveals the molecular basis of anion selectivity. Nature 2002, 415:287-294.

16. Smith AJ, Reed AA, Loh NY, Thakker RV, Lippiat JD: Characterization of Dent's disease mutations of CLC- 5 reveals a correlation between functional and cell biological consequences and protein structure. Am J Physiol Renal Physiol 2009, 296:F390-F397.

17. Wu F, Roche P, Christie PT, Loh NY, Reed AAC, Esnouf RM, Thakker RV: Modeling study of human renal chloride channel ( $\mathrm{hCLC}-5)$ mutations suggests a structural-functional relationship. Kidney Int 2003, 63:1426-1432.

18. Hryciw DH, Wang Y, Devuyst O, Pollock CA, Poronnik P, Guggino WB: Cofilin interacts with $\mathrm{ClC}-5$ and regulates albumin uptake in proximal tubule cell lines. J Biol Chem 2003, 278:40169-40176.

19. Devuyst O, Christie PT, Courtoy PJ, Beauwens R, Thakker RV: Intra-renal and subcellular distribution of the human chloride channel, CLC-5, reveals a pathophysiological basis for Dent's disease. Hum Mol Genet 1999, 8:247-257

20. Günther W, Lüchow A, Cluzeaud F, Vandewalle A, Jentsch TJ: CIC-5, the chloride channel mutated in Dent's disease, colocalizes with the proton pump in endocytotically active kidney cells. Proc Natl Acad Sci USA 1998, 95:8075-8080.

21. Christensen El, Birn H: Megalin and cubilin: multifunctional endocytic receptors. Nat Rev Mol Cell Biol 2002, 3:256-266.

22. Piwon N, Gunther W, Schwake M, Bösl MR, Jentsch TJ: ClC-5 Cl-channe disruption impairs endocytosis in a mouse model for Dent's disease. Nature 2000, 408:369-373.

23. Wang SS, Devuyst O, Courtoy PJ, Wang T, Wang H, Wang Y, Thakker RV, Guggino S, Guggino WB: Mice lacking renal chloride channel, CLC-5, are a model for Dent's disease, a nephrolithiasis disorder associated with defective receptor-mediated endocytosis. Hum Mol Genet 2000, 9:2937-2945

24. Günther W, Piwon N, Jentsch TJ: The CIC-5 chloride channel knock-out mouse - an animal model for Dent's disease. Pflugers Arch 2003, 445:456-462.

25. Hara-Chikuma M, Wang Y, Guggino SE, Guggino WB, Verkman AS: Impaired acidification in early endosomes of CIC-5 deficient proximal tubule. Biochem Biophys Res Commun 2005, 329:941-946.

26. Novarino G, Weinert S, Rickheit G, Jentsch TJ: Endosomal chloride-proton exchange rather than chloride conductance is crucial for renal endocytosis. Science 2010, 328:1398-1401.

27. Christensen El, Devuyst $O$, Dom G, Nielsen $R$, Van der Smissen $P$, Verroust $P$ Leruth M, Guggino WB, Courtoy PJ: Loss of chloride channel CIC-5 impairs endocytosis by defective trafficking of megalin and cubilin in kidney proximal tubules. Proc Natl Acad Sci USA 2003, 100:8472-8477.

28. Jentsch TJ: Chloride and the endosomal-lysosomal pathway: emerging roles of CLC chloride transporters. J Physiol 2007, 578:633-640.

29. Gailly P, Jouret F, Martin D, Cosyns JP, Nishita T, Antignac C, Willnow TE, Courtoy PJ, Scheinman SJ, Christensen El, Devuyst O: Type III carbonic anhydrase: A novel renal isoform that plays a role in proximal tubule dysfunction. Kidney Int 2008, 74:52-61.

30. Nielsen R, Courtoy PJ, Jacobsen C, Dom G, Rezende Lima W, Jadot M, Willnow TE, Devuyst O, Christensen El: Endocytosis provides a major alternative pathway for lysosomal biogenesis in kidney proximal tubular cells. Proc Natl Acad Sci USA 2007, 104:5407-5412.

31. Cochat P, Pichault V, Bacchetta J, Dubourg L, Sabot JF, Saban C, Daudon M, Liutkus A: Nephrolithiasis related to inborn metabolic diseases. Pediatr Nephrol 2010, 25:415-424

32. Pham PCT, Devuyst O, Pham PTT, Matsumoto N, Shih RNG, Jo OD, Yanagawa N, Sun AM: Hypertonicity increases CIC-5 expression in mouse medullary thick ascending limb cells. Am J Physiol Renal Physiol 2004, 287: F747-F752.

33. Devuyst $\mathrm{O}$, Pirson Y: Genetics of hypercalciuric stone forming diseases. Kidney Int 2007, 72:1065-1072.

34. Scheinman SJ, Cox JPD, Lloyd SE, Pearce SHS, Salenger PV, Hoopers RR, Bushinsky DA, Wrong O, Asplin JR, Langman CB, Norden AGW, Thakker RV: Isolated hypercalciuria with mutation in CLCN5: Relevance to idiopathic hypercalciuria. Kidney Int 2000, 57:232-239. 
35. Sayer JA, Carr G, Simmons NL: Calcium phosphate and calcium oxalate crystal handling is dependent upon CLC-5 expression in mouse collecting duct cells. Biochim Biophys Acta 2004, 1689:83-90.

36. Vandewalle A, Cluzeaud F, Peng KC, Bens M, Lüchow A, Günther W, Jentsch TJ: Tissue distribution and subcellular localization of the CIC-5 chloride channel in rat intestinal cells. Am J Physiol Cell Physiol 2001, 280 C373-C381.

37. Vanden Hove MF, Croizet-Berger $K$, Jouret F, Guggino SE, Guggino WB, Devuyst O, Courtoy PJ: The loss of the chloride channel, CIC-5, delays apical iodide efflux and induces an euthyroid goiter in the mouse. Endocrinology 2006, 147:1287-1296.

38. Leahey AM, Charnas LR, Nussbaum RL: Nonsense mutations in the OCRL-1 gene in patients with the oculocerebrorenal syndrome of Lowe. Hum Mol Genet 1993, 2:461-463.

39. Zhang X, Hartz PA, Philip E, Racusen LC, Majerus PW: Cell lines from kidney proximal tubules of a patient with Lowe syndrome lack OCRL inositol polyphosphate 5-phosphatase and accumulate phosphatidylinositol 4,5-bisphosphate. J Biol Chem 1998, 273:1574-1582.

40. Ungewickell AJ, Majerus PW: Increased levels of plasma lysosomal enzymes in patients with Lowe syndrome. Proc Natl Acad Sci USA 1999, 96:13342-13344

41. Lowe M: Structure and function of the Lowe syndrome protein OCRL1. Traffic 2005, 6:711-719.

42. Erdmann KS, Mao Y, McCrea HJ, Zoncu R, Lee S, Paradise S, Modregger J, Biemesderfer D, Toomre D, De Camilli P: A role of the Lowe syndrome protein OCRL in early steps of the endocytic pathway. Dev Cell 2007, 13:377-390.

43. Jänne PA, Suchy SF, Bernard D, MacDonald M, Crawley J, Grinberg A, Wynshaw-Boris A, Westphal H, Nussbaum RL: Functional overlap between murine Inpp5b and Ocrl1 may explain why deficiency of the murine ortholog for OCRL1 does not cause Lowe syndrome in mice. J Clin Invest 1998, 101:2042-2053

44. Frishberg Y, Dinour D, Belostotsky R, Becker-Cohen R, Rinat C, Feinstein S, Navon-Elkan P, Ben-Shalom E: Dent's disease manifesting as focal glomerulosclerosis: Is it the tip of the iceberg? Pediatr Nephrol 2009, 24:2369-2373

45. Moulin $\mathrm{P}$, Igarashi $\mathrm{T}$, Van Der Smissen $\mathrm{P}$, Cosyns JP, Verroust $\mathrm{P}$, Wrong $\mathrm{O}$, Thakker RV, Scheinman SJ, Courtoy PJ, Devuyst O: Altered polarity and expression of $\mathrm{H}^{+}$-ATPase without ultrastructural changes in kidneys of Dent's disease patients. Kidney Int 2003, 63:1285-1295.

46. Igarashi T: Fanconi syndrome. In Pediatric Nephrology. Edited by: Avner ED, Harmon WE, Niaudet P, Yoshikawa N. Springer-Verlag, Berlin Heidelberg; , 6 2009:1039-1067.

47. Frymoyer PA, Scheinman SJ, Dunham PB, Jones DB, Hueber P, Schroeder ET: X-linked recessive nephrolithiasis with renal failure. N Engl J Med 1991, 325:681-686.

48. Raja KA, Schurman S, D'mello RG, Blowey D, Goodyer P, Van Why S, PloutzSnyder RJ, Asplin J, Scheinman SJ: Responsiveness of hypercalciuria to thiazide in Dent's disease. J Am Soc Nephrol 2002, 13:2938-2944.

49. Blanchard A, Vargas-Poussou R, Peyrard S, Mogenet A, Baudouin V, Boudailliez B, Charbit M, Deschesnes G, Ezzhair N, Loirat C, Macher MA, Niaudet $\mathrm{P}$, Azizi M: Effect of hydrochlorothiazide on urinary calcium excretion in Dent disease: an uncontrolled trial. Am J Kidney Dis 2008, 52:1084-1095.

50. Cebotaru V, Kaul S, Devuyst O, Cai H, Racusen L, Guggino WB, Guggino SE: High citrate diet delays progression of renal insufficiency in the CIC-5 knockout mouse model of Dent's disease. Kidney Int 2005, 68:642-652.

doi:10.1186/1750-1172-5-28

Cite this article as: Devuyst and Thakker: Dent's disease. Orphanet Journal of Rare Diseases 2010 5:28.

\section{Submit your next manuscript to BioMed Central and take full advantage of:}

- Convenient online submission

- Thorough peer review

- No space constraints or color figure charges

- Immediate publication on acceptance

- Inclusion in PubMed, CAS, Scopus and Google Scholar

- Research which is freely available for redistribution

Submit your manuscript at www.biomedcentral.com/submit
Biomed Central 